\title{
Palakesi obiugri mütoloogiast I
}

\author{
Aado Lintrop
}

Üks möödunud sajandil üles kirjutatud mansi muistend algab nii:

"Elavad tundras mätta peal eite-taati. Neil on lumivalge ronk. Aga maja ümber on igal pool vesi. Maad pole näha. Taat ei käi õues, ei tea, milline on maailm. Elavad nõnda, elavad, kuni ühel päeval kostab ülemisest taevast mürin. Taat vaatab aknast välja ja näeb, et ülevalt, päris taevast enesest lendab alla raudne kaur,(1) laskub vette, otsib maad. Ujub ja ujub seal all, tõuseb pinnale, aga maad ei leidnud. Ahmib õhku ja sukeldub uuesti. Ujub ja ujub, tõuseb pinnale - jälle asjata, maad pole. Tõmbab natuke hinge, siis sukeldub kolmandat korda. Aga kui pinnale tõuseb, siis ahmib nii kõvasti õhku, et kõri rebeneb. Noka otsa aga ilmub tükike maad. Tõuseb lendu ja kaob sellega taevasse.

Eite-taati heidavad magama. Kui nad hommikul ärkavad, kostab taevast jälle mürin. Taat vaatab aknast välja, näeb, et taevast lendab alla raudne tuttpütt ja laskub vette. Ujub ja ujub, aga kui pinnale tõuseb, pole tal mitte midagi. Puhkab veidi ja sukeldub uuesti. Jälle ujub ja ujub, tõuseb pinnale - ikka pole midagi. Tõmbab hinge ja sukeldub kolmandat korda. Kui pinnale tõuseb, siis ahmib nii kõvasti õhku, et pähe rebeneb suletutt, aga noka otsa kasvab suur tükk maad. Ta nühib nokka vastu mättal olevat maja ja lendab tagasi taevasse.

Eite-taati heidavad magama. Kui nad hommikul ärkavad, on maad juba

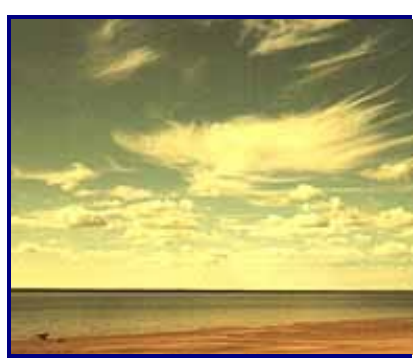

Pilved Voikari järve kohal.

Foto A. Lintrop 1989. jalatäie jagu. Kui järgmisel päeval tõusevad, on maa juba nii suureks kasvanud, et ulatab silmapiirini. Kolmandal päeval vaatavad eite-taati aknast välja - vett enam pole, vesi on kõikjal maaks muutunud. Taat ütleb lumivalgele rongale: "Sa mine ja vaata, milline maa on!" Ronk läheb, on terve tunni ära - maa on juba nii suur. Eite taati heidavad jälle magama, tõusevad jälle üles ja saadavad lumivalge ronga jälle maa suurust vaatama. Ronk tuleb alles keskpäevaks tagasi - maa on juba nii suur.

Kolmandal päeval ärkavad, jälle ütlevad rongale: "Mine ja vaata, kui suur maa juba on!" Juba läheb päike looja, aga ronk pole veel tagasi. Alles päris öö hakul ilmub ta välja, kuid on üleni mustaks muutunud. Taat küsib rongalt: "Millega sa teel olles hakkama said?" Ronk vastab: "Millega ma hakkama sain? Inimene suri ära, ma sõin teda ja muutusin mustaks." - "Sellepärast, et sa inimest sõid, kasi siit minema! Seni, kuni elavad ilmas inimesed, ära julgegi metsloomi tappa, ära julgegi kalu tappa. Seal, kus inimene tapab metslooma, pead sa verepritsmetega kaetud mullaga oma nälga

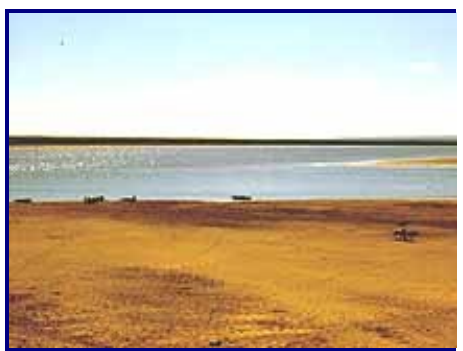

Voikar suubub Mägiobi jõkke. Foto A.Lintrop 1989. kustutama, ja tulevad päevad, mil sa heidad söömata magama!" Selle peale läks ronk metsa ja elab seal tänaseni.

Nüüd läheb eit mätta peal olevast majast välja. Kui tagasi tuleb, ütleb taaile: "Vanamees, maja taha on mingi põõsas kasvanud." Taat vastab: "Millised on ta juured, millised on oksad? Too ta siia!" Eit kaevab puu välja, toob tuppa. Taat tunneb selle ära - see on kääbusmänd. Ütleb eidele: "Vii välja, istuta tagasi!"

Taat ise ei käi üldse õues. Heidab koos eidega magama, aga kui ärkab, pole eite kusagil. Kas läks kuhugi või mis juhtus, taat ei leia teda ja elab üksi edasi. Elab nõnda neli-viis nädalat, viimaks hakkab tal 
igav. Kuigi ta välja minna ei tohi, tahab ta naist üles otsida. Läheb ukseni, aga õuest hüüab naine talle: "Ära tule välja! Mul on poeg, poiss on juba nii suur, et jaksab orava maha lüüa. Tulen nädala pärast koju, aga sina püsi toas!" Eit on veel ühe nädala väljas, siis tuleb koos pojaga tuppa. Poiss on juba nii suur, et hakkab jooksma.

Laulude inimene, muistendite inimene, miks sa nii kiiresti kasvad? Eite-taati elavad edasi õnnelikult. Nende poeg on juba nii suur, et võib metsloomadele jahti pidada. Tahumiseks sobiliku puu südamikust tehakse talle vibu, ta hakkab vee- ja metsloomi küttima.

Ükskord küsib taat: "Mis me pojale nimeks paneme?" Eit vastab: "Kui meil oleks tütar, siis paneksin talle küll nime, aga pojale peaks vist isa nime andma." Taat ütleb: "Mis nimi talle siis panna? Saagu ta nimeks Tari-pes'h-nimala-s'av.""

Isa näpunäidete järgi saab loo keskseks kangelaseks tõusnud Tari- pes'h endale lennuvõimelise hobuse ning külastab järgemööda Vetevürsti, Kuuvanameest, Päikesenaist ja teisi üleloomulikke olendeid, võitleb mõnega neist, mõne aga kavaldab üle, saades endale naisteks võidetud vastaste naised ja tütred. Lõpuks jõuab ta koos kuue naisega õnnelikult tagasi vanemate juurde. Need võtavad poja pidusöögiga vastu. Peo ajal ütleb ema: "Saagu inimene nüüdsest olema endises maailmas, saagu inimene olema praeguses maailmas, saagu kõikjal olema naiste paigad ja meeste paigad, mida asustagu palju vaesetes kasukates naisi ja palju vaesetes kasukates mehi. Ning hakaku nad sulle ohvriks tooma põdrapulle ja põdralehmi!" Järgmisel hommikul ütleb ema: "Sa, pojake, jääd nüüd siia, alumisse taevasse, meie aga läheme ülemisse taevasse. Alumises taevas saab sinust mees, kes kaitseb maailma - Mir-susne-hum,(2) sinu isa saab ülemises taevas kõrgeimaks jumalaks - Numi-Toorumiks, minust aga saab Kaltesh." (Shestalova-Fidorovitsh 1992: 5-6, 22-23). Lugu meenutab paapuate muistendeid müütilisel loomisajal tegutsevatest dema-jumalustest, kes omavahel suheldes ja üksteist tappes panevad aluse eri suguharudele, kultuurtaimedele, koduloomadele ja hilisemale maailmakorrale. Jutu algus on tähelepanuväärne veel sellegi poolest, et sisaldab mitmeid seletusmuistendite algeid - miks on kauril kurk punane, kuidas tekkis tuttpütile tutt pähe, miks ronk on must.

Obiugrilaste (hantide ja manside) taevaga seotud jumalus esineb sageli nimede Numi-Toorum, Numi-Taarõm, Numi-Tuurõm, Num-Toorõm all (num või numi tähendab neis keeltes 'ülemine, pealmine', toorumi tähendused on 'ilm, taevas, jumal'). Mitmetes muistendites ja müütilistes lauludes esineb Numi-Toorum kõrgeima jumalusena, kes elab taeva ülemisel korrusel asuvas linnas. Sageli kõnetatakse teda kui seitsmendas taevas roovlati ja unkaga majas elavat helget isa (vt. kasvõi Steinitz 1939: 384-385). Mõnede muistendite kohaselt on tema

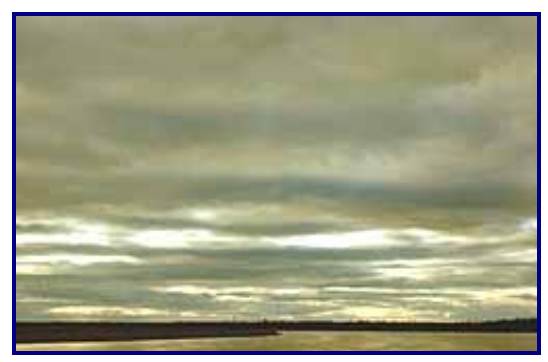

Õhtu Voikaril. Foto A. Lintrop 1989. see, kes käsib lindudel (kauril ja punakurk-kauril) või kauriks moondunud kuradil (Kul'-ootõril) ürgmere põhjast maad otsida. Kuna pinnale toodud ja kasvama hakanud maa algul vees ringi keerleb, pole seal võimalik elada. Numi-Toorum viskab maa peale oma nööpidega kaunistatud vöö, mis maa oma raskusega paigale vajutab. Vööst saavad Uurali mäed. (Karjalainen 1918: 298; Tshernetsov 1987:153). Numi-Toorum osaleb ka inimese loomisel, kusjuures tema vastane on Kul' või Khul'-ootõr (obiugri $k u l^{\prime} \sim k h u l^{\prime}=$ kurat, kuri vaim, komi $k u l^{\prime}=$ kurat, paharett, näkk, vetevaim; selle sõnaga on suguluses soome koljo $=$ hiiglane, koletis; udmurdi $k \tilde{o} l^{\prime}=$ nakkushaiguse või palaviku vaim, eesti koll). Ühes Munkácsi poolt kirja pandud müütilise laulus esineb Kul'-aatõr taevajumala pojana, kes tüütab isa palvega saada jumaluseks, kellele inimesed kõige rohkem ohverdaksid. Viimaks heidab isa ta taevast alla. Kul' pääseb meres valitsevaist ohtudest ja loob paremas taskus olnud hõberahadest seitse raudvibudega meest ning piiritu linna. Maal sekkub $K u l^{\prime}$ loomisprotsessi, mistõttu inimene saab endale algselt sarvainega kaetud ihu asemele hapra ja sureliku savist keha. 
(Karjalainen 1918: 346.) Varianditi palub $K u l^{\prime}$ taevajumalalt luba elusolendeid luua. Kui luba ei anta, teeb ta maa sisse lõhe, millest roomavad välja maod, konnad ja sisalikud. Ka hunt olevat tema looming (Karjalainen 1918: 356). Tshernetsov aga esitab variandi, kus Numi-Toorum ja Kul' koos inimesi teevad, kusjuures Toorum kasutab materjaliks lehist, Kul' aga savi. Seejärel lähevad nad oma kätetööga Toopal-ooika (Taapal ooika) ehk Mikol-Toorumi juurde, et see inimesed elustaks. Viimane võtab puust inimese, paneb selle seisma seljaga enda poole, mistõttu see peale elustamist metsa jookseb ja metshiiuks menkviks saab. Savist inimese paneb ta aga seisma näoga enda poole ning sellest saab inimene (Tshernetsov 1987: 153).

Ent paljudes tekstides esineb kõrgeima jumalusena hoopis Kors-Toorum (Numi-Kors $\sim$ Kwors $\sim$ Kworõs). Gondatti järgi lõi tema taeva, maa, vee, tule, päikese, kuu ja tähed ning käskis kauril maa järele sukelduda (Karjalainen 1918: 298). Munkácsi poolt Sosva-äärsete manside juures üleskirjutatud muistendite kohaselt lasi taevajumal Numi-Kworõs taeva ja maa vahele kolm poega - NumiTaarõmi, S'ahl-Taarõmi ja T'apõl-ooika ning nende õe Kaltõs'-eekwä (ibid: 297, s'ahõl tähendab mansi keeles äikest). Üks tema poolt samas piirkonnas 1889 aastal kogutud laul algab aga nii:

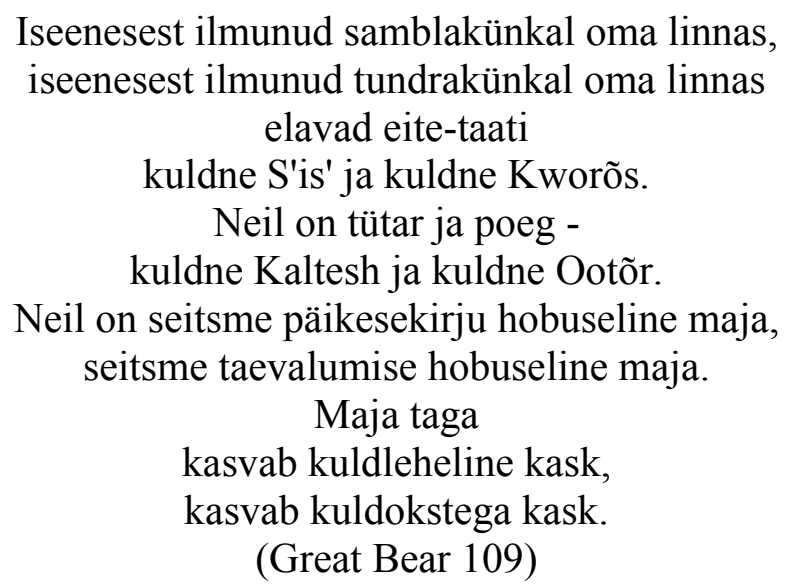

Tshernetsov toob oma päevikus ära järgmise geneoloogia: Kos'har-Toorumi poeg on Kors-Toorum, Kors-Toorumi pojad on Numi-Toorum ja Taapal (Toopal) ooika ehk Mikol-Toorum, kusjuures Numi-Toorum on noorem. Tema pojad on seitse Toorumit, kellest kõige noorem on Mir-susne-hum ehk eekva põgris' (Tshernetsov 1987: 153). Sageli esineb Kwores epiteediga sorni (kuldne). Üks möödunud sajandil kogutud müütiline laul kirjeldab taeva ja maa vahel sõnumeid edasi toimetava "kõrgelt käiva tiivulise Kalmi" taevajumala juurde jõudmist nii:

Kuus hõbenurkadega ust ta avas, seitsmenda hõbenurkadega ukse avas.

Astus ukselisse majja, vaatas laudpõrandaga maja põranda keskele:

seal on seitse kuldäärelist lauda.

Seitsme kuldäärelise laua ääres

istub kuldne Kwores-isa pühal kuldjalgsel troonil.

Püha kuldsete harudega sau toetub vastu ta nägu paremalt poolt.

(Shestalova-Fidorovitsh 1992: 25.)

Kannisto poolt 1905. aastal üles kirjutatud karupeielaulus kujutatakse taevajumalat ja ta eluaset nõnda: 
Karutüdrukut kasvatatakse.

Mõõtmata paljust punasest siidist külluslikus pesas ta elab õnnelikult, mõõtmata paljust punasest kalevist külluslikus pesas ta istub.

Nõnda istudes isa ta ette astus.

Isa tütre poole suu avas:

"Tütreke, homme lähen ma oma sooblipüüniseid, oma loomapüüniseid vaatama, homme sa ole toas, raudlukuga, kivilukuga seitsme maja ust ära purusta!"

Nad magasid.

Kaua magasid või vähe magasid, isa ülestõusmine kostis,

ta seitsmes majas kõndimine kostis.

(Tüdruk) vaatas: tuule tuulatud rõiavd

karusnahksetele õlgadele, sooblinahksetele õlgadele ta paistis panevat.

Tuule tuulatud vöö

karusnahksele vööle, sooblinahksele vööle ta paistis vöötavat.

Tuule tuulatud mütsi, vihma leotatud mütsi ta paistis (pähe) panevat.

Kivilukuga, raudlukuga seitsme maja uksest ta välja astus.

kivilukud, raudlukud kõik ta lukustas.

Meistrimehe tehtud suusad (3) ette ta asetas.

Vägeva piksekõmina kõlades, tugeva piksekõmina kõlades ta läks.

(Kannisto, Liimola 1958: 28-30)

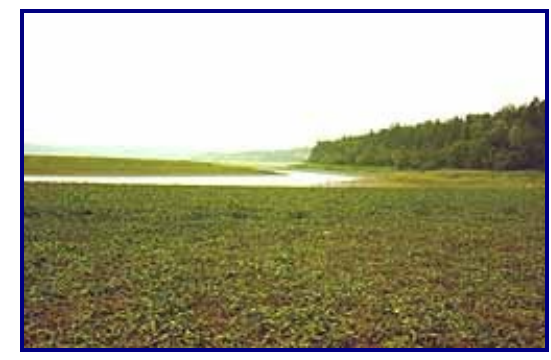

Jõeluht Vasjuhovo küla lähedal. Foto A. Lintrop 1989.
Taevajumala naisena esineb sageli Kaltesh-eekva (eekva = naine, eit). Tavaliselt on taevasel paaril seitse poega, tütardest eriti ei räägita (kuigi näiteks Kazõmi jõe haldjat Kassum-imi peetakse Numi-Toorumi tütreks). Mitmete muistendite kohaselt sünnitas Kaltesh seitsmenda poja pärast seda, kui Numi-Toorum ta kas kõrkuse (näiteks nõudis Kaltesh ühes muistendis endale maja, mis oleks ehitatud kõigi maa peal elavate loomade luudest) või abielurikkumise pärast taevast alla heitis (Toporov1989: 171). Poeg sündis maa ja taeva vahel, temast sai inimestele kõige lähem jumalus Maailmavaatav mees. Kaltesh aga asus elama Obi keskjooksule Kaltasani küla lähedale, kus veel käesoleva sajandi algul oli tähtsaim temale pühendatud ohverdamispaik. Kuigi Kaltesh esineb mõnel pool ka Numi-Toorumi õe või tütrena, on ettekujutused temast ja ta elupaigast muus osas sarnased. Handi karupeiete laulu kaudu tutvustab ta ennast nõnda:

...toituandva Obi ääres, seal algab

hanekisaga täidetud looklev jõeharu, pardikisaga täidetud looklev jõeharu seal algab.

Lookleva jõeharu ääres, hanekisaga täidetud jõeharu ääres, pardikisaga täidetud jõeharu ääres mina, haldjas, elan.

Jõevoolust riivatud voolulisel kaldajärsakul, tuulest riivatud tuulisel kaldajärsakul, 


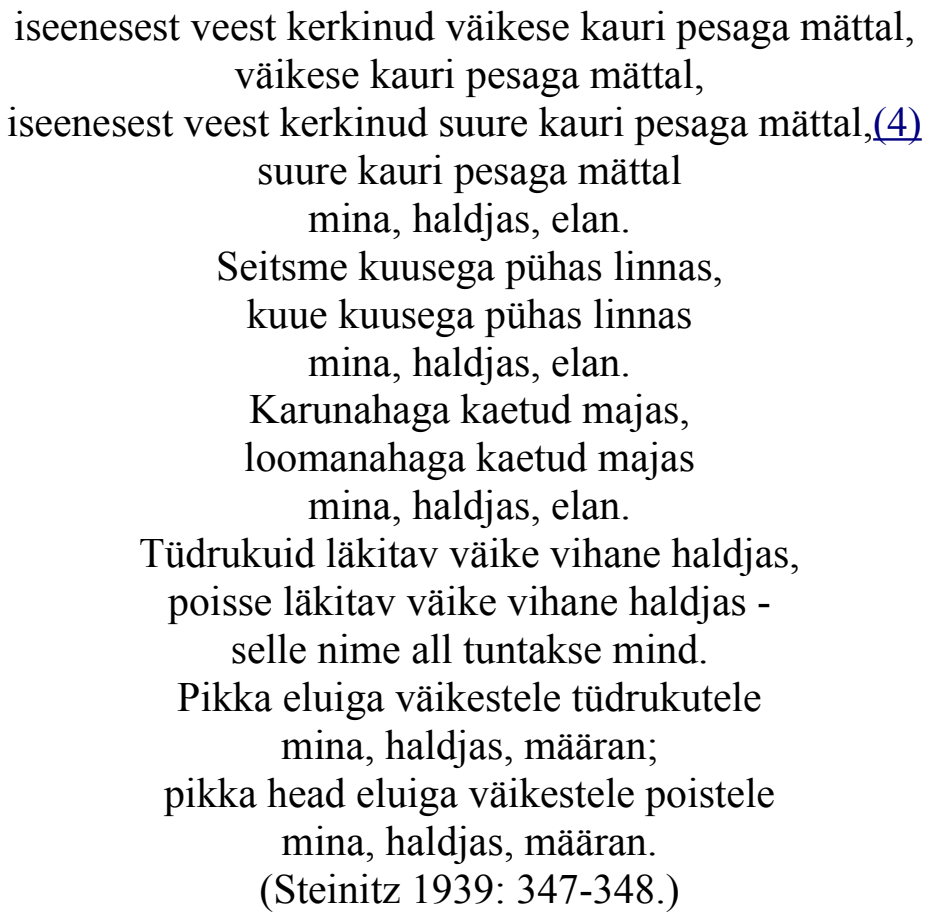

Uskumuste kohaselt oli Kaltesh see, kes saatis inimestele kõigi sündivate laste hinged. Tsiteeritud laulus tähistavad seda sõnad tüdrukuid läkitav väike vihane haldjas, poisse läkitav väike vihane haldjas. Samuti määras ta kindlaks inimese eluea (seda märgivad värsid: pikka eluiga väikestele tüdrukutele mina, haldjas, määran; pikka head eluiga väikestele poistele mina, haldjas, määran.). Inimese saatuse ja eluea märkis ta kas kuldkirjalisele märgisauale (Karjalainen 1918: 249) või raamatusse. Enne tema poolt määratud päevade möödumist ei tohtinud keegi surra. Kalteshi poole pöördusid abipalvetega rasedad ja sünnitajad (ibid: 248). Sellisena on ta üsna sarnane sölkupi Eluandja eide (vt. Prokofjeva 1961: 55-61) või evengi Ilmaeidega.

Muistendites esineb Kaltesh sageli Maailmavaatava mehe ema või tädina, kusjuures see, kes keegi tegelikult on, öeldakse otsesõnu välja alles loo lõpus. Aga algavad need nii: elas mees koos õega; või -ühes kauges paigas, ühes ilmaotsas elas eit oma nõbuga; või - elas üks eit koos oma nõbuga (kõik Steinitz 1939). Näiteks ühe Steinitzi poolt üles kirjutatud jutu algus:

"Elas $m o s^{\prime}$-mees(5) koos oma õega. Pikka aega elasid nad kaua, lühikest aega kiiresti. Sel ajal, kui nad niimoodi elasid, täitis vend paljudel Toorumi poolt loodud päevadel paljusid metsas olevaid aitu karusnahkadega, täitis paljusid mägimetsades olevaid aitu. Pärast seda, kui vend oli ühel päeval jälle metsa käima läinud, astus sisse Seitsme Soobli Kõrgune Vägilane ja ütles $m o s$ '-mehe õele: "Otsi mu peast täisid!" Naine hakkas ta peast täisid otsima. Kui ta oli pikka või lühikest aega täisid otsinud, ütles ta: "Nüüd aitab, mine

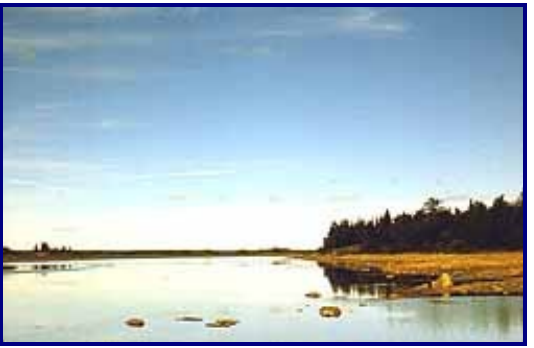

Voikari ülemjooksul. Foto A. Lintrop 1989. koju! Kui mu vend tuleb, mu vend hakkab riidlema." Vaevalt oli nende jutt lõppenud, kui mees läks ära. Võis kuulda, et vend on tulemas. Ta lõi oma viie loomanahaga kaetud suusataldu kokku ja seitsmekordne kaja raksatas otsekui kildudeks purunedes, kuuekordne kaja raksatas otsekui kildudeks purunedes. Seejärel raputas vend jääkillud ja lume oma kasukalt maha ja astus tuppa. "Ah, õde, su majas kummitab silmade ja kõrvade ees!" Õde ütles: "Olen oma mustad riided selga pannud." Seepeale jättis vend ta rahule. Siis nad sõid, jõid ja heitsid magama." 
Järgmisel päeval kordus sama. Ent kolmandal päeval ei läinud Seitsme Soobli Kõrgune Vägilane minema, vaid ootas venna ära ja küsis õde endale naiseks. Vend ütles: "Kui mu õde tahab, las läheb. Mina takistama ei hakka." Vägilane pressis õe endale taskusse ja viis ta minema. Õde sünnitas poja, kes kasvas nii kiiresti, et Seitsme Soobli Kõrgune Vägilane hakkas kahtlema, kas ta ikka on poisi isa. Poisil seisis ees rida katsumusi, näiteks pidi ta võistlema oma seitsme vennaga kivi lingutamises. Enne võistlust pöördus poiss oma seitsmendas taevas roovlati ja unkaga majas elava helge isa poole, öeldes: "Kui sa mind tõepoolest saja tiivulise vaimu käskijaks, kui sa mind tõepoolest saja jalalise vaimu käskijaks oled pannud, siis kukkugu nende visatud lingukivi minu nina ette maha." Nagu Maailmavaatav Mees/Naise eide Poeg/Naise Nõbu kunagi, võitis poiss oma vennad. Seejärel saatis isa ta koos poegadega seitsme kivisilmse vägimehe linna. Seal põgenes poiss kinnivõtjate küüsist ning ujus kaurina(6) tagasi koju. Lugu lõppeb suure pidusöögiga, mille ajal onu ütleb poisile: "Sa mine nüüd oma maale! Hommikul saamata jäänud ohvrid võta vastu õhtul, õhtul saamata jäänud ohvrid võta vastu hommikul!" Siis ütleb ta oma õele: "Sa mine oma iseenesest veest kerkinud kauri pesaga mättale, oma iseenesest veest kerkinud jääkauri pesaga mättale(7). Hommikul saamata jäänud ohvrid võta vastu õhtul, õhtul saamata jäänud ohvrid võta vastu hommikul!" Onu ütleb: "Ise lähen oma jooksva hobuse kujulisse linna, oma sammuva hobuse kujulisse linna. Väikeste tüdrukute hingi peatades olen seal, väikeste poiste hingi peatades elan seal." (Steinitz 1939: 244-263.) Nagu eespool näiteks toodud mansi muinasjutukatkendis, nii jagavad jumalused-haldjad loomisajastu lõppedes ka siin omavahel elupaigad ja funktsioonid. On selge, et jooksva/sammuva hobuse kujulises linnas elav onu on Püha Linna Taat (vt. Steinitz op. cit.: 385 jooksva hobuse kujulises linnas, sammuva hobuse kujulises linnas mina, haldjas, elan), kellest uskumuste kohaselt sõltus suuresti inimelu kestus maa peal. Nimelt oli tema viimane, keda surija hing enne Allilma Isanda valdustesse jõudmist külastas (Schmidt 1989: 223). Selles valguses muutub arusaadavamaks ta lubadus väikeste laste hingi peatada. Loomislugude linnu pesa kõrvale saadetud naine on Kaltesh. Sellest tunnistab selgesti teises handi muistendis esinev vormel: "Toitu andvale Obile, kala andvale Obile, nelja Obi-neeme hargnemiskohta mine! Hanekisaga täidetud looklevatele jõeharudele, pardikisaga täidetud looklevatele jõeharudele mine! Oma iseenesest veest kerkinud kauri pesaga mättale, oma iseenesest veest kerkinud jääkauri pesaga mättale mine! - Väikeste tüdrukute, väikeste poiste eluiga kindlaks määrates ela seal. Kauaks elama määratud väikestele poistele määra pikk iga, kauaks elama määratud väikestele tüdrukutele määra pikk iga!" (Steinitz 1939: 301-302.) Lugude peategelane aga on Maailmavaatav Mees. Talle ütleb onu:"Sa, nõbu, mine toitu andva Obi, kala andva Obi ülemjooksule, oma kuldse muruga, kuldse rohuga kaetud neemele, oma kevadiste metsisekukkede sulgedega kaetud eelmägedesse, sügiseste metsisekukkede sulgedega kaetud eelmägedesse, oma vibunööri otsas rippuvasse linna, oma kinganööri otsas rippuvasse linna, oma kuukirjusse pühasse majja, oma päikesekirjusse pühasse majja! Oma kuldkabjalise laua taga istu oma kevadistest oravanahkadest, sügisestest oravanahkadest püha raamatut lugedes! - - Oma kuukirju püha hobuse seljas ratsuta ümber võruna keerleva ringikujulise maailma, ratsuta ümber võruna keerleva haldjate ilma!"(8) (ibid: 300-301.)

Eespool juba tsiteeritud Munkácsi poolt kogutud laulus esitatakse Kalteshit ja Maailmavaatavat Meest kui õde-venda. Esimest kirjeldatakse nõnda:

Vanem õde kuldne Kaltesh

astub õue, laseb patsid alla ühe suudmega seitse Obi voolab, ühe suudmega seitse merd tõuseb. 


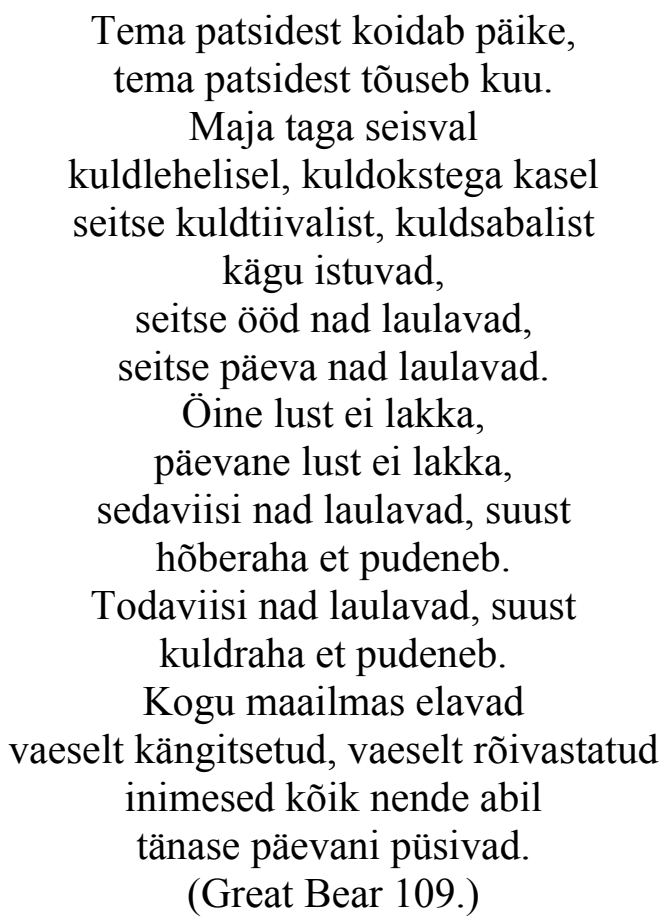

Läheb edasi...

\section{Kirjandus:}

Great Bear 1993. The Great Bear. A Thematic Anthology of Oral Poetry in the Finno-Ugrian languages. Pieksamäki.

Kannisto, A., Liimola, M. 1958. Wogulische Volksdichtung IV. Bärenlieder. SuomalaisUgrilaisen Seuran Toimituksia 114. Helsinki.

Karjalainen, K. F. 1918. Jugralaisten uskonto. Suomensuvun uskonnot III. Porvoo.

Prokofjeva J. D. 1961. Predstavlenija selkupskih shamanov o mire po rissunkam i akvareljam selkupov. Sbornik Muzeja antropologii i etnografii, t. XX. Leningrad.

Schmidt, É. 1989. Bear Cult and Mythology of the Northern Ob-Ugrians. Uralic Mythology and Folklore. Budapest.

Sokolova Z. P. 1983. Sotsialnaja organizatsija hantov i mansi v XVIII-XIX vv. Problemõ fratrii i roda. Moskva.

Sokolova Z. P. 1987. K proishozhdeniju obskih ugrov i ih fratrii (po dannõm folklora).

Traditsionnõje verovanija i bõt narodov Sibiri XIX natshalo XX v. Novosibirsk, s. 118-133.

Steinitz, W. 1939. Ostjakische Volksdichtung und Erzählungen aus Zwei Dialekten. 1. Teil.

Õpetatud Eesti Seltsi Toimetused XXXI. Tartu.

Shestalova-Fidorovitsh O. 1992. Svjashtshennõi skaz o sotvorenii zemli. Perevod O. ShestalovoiFidorovitsh. Leningrad - Hantõ-Mansiisk.

Toporov, V. N. 1989. About a Probable Ob-Ugrian Reflection of the Iranian Mithra. Uralic Mythology and Folklore. Budapest.

Tshernetsov V. T. 1987. Istotshniki po etnografii Zapadnoi Sibiri. Tomsk. 
1. Nagu allpool selgub, on siin mõeldud punakurk-kauri.

2. Maailmavaatav Mees, muistendite kohaselt taevajumala Numi-Toorumi ja ta naise Kaltesh-eekva noorim poeg, kes oma lendava hobuse seljas maa kohal ratsutab ja inimesi kaitseb. Temast lähemalt allpool.

3. Edaspidi on laulus seoses taevajumala suusatamisega mitmel korral rõhutatud, et kui poleks meistrimehe tehtud suusad, siis puruneksid need tükkideks.

4. vt. märkusi 5 ja 6.

5. Mos' ja por on kahe obiugri eksogaamse sugukonnaülese grupi ehk fraatria nimed.

Traditsioonilise ühiskonna fratriaalne jaotus puudus vaid Konda-äärsetel mansidel (Sokolova 1987:

121). Teistel obiugrilaste aladel oli duaalne eksogaamia valitsev veel XVIII saj. lõpul (Sokolova 1983: 164).

6. Karjalainen kirjutab Munkácsile viidates, et mõnes loomismuistenis sukeldus ürgmere põhja kauri kuju võtnud eide-taadi poeg (= Maailmavaatav mees), mõnes Khul'-ootõr (Karjalainen 1918: 298). Tõenäoliselt võib kõnealusesse juttu põimitud kauri kujul põgenemise motiivi võta ka loomisloole viitava mementona. Kauri ja Maailmavaatava Mehe seosele viitab kaudselt ka Kalteshi elupaigaga seostatav iseenesest veest kerkinud kauri pesaga mätas (vt. allpool).

7. Vihje maailmaloomise loole. Väljend iseenesest veest kerkinud peab tähendama, et mätas kauri pesaga oli olemas juba enne aegade algust, vastandina maale, mille kaur ürgmere põhjast pinnale tõi.

8. Samad Kalteshi ja Maailmavaatava Mehe elupaiku kirjeldavad vormelid korduvad ka karupeiete lauludes (vt. ka Steinitz 1939: 339-341, 347-348). 